\title{
Structural and Electronic Effects Due to Fluorine Atoms on Dibenzotetraaza-Annulenes Complexes
}

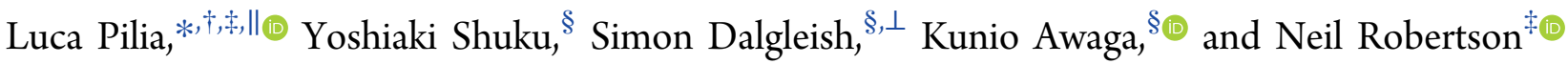 \\ ${ }^{\dagger}$ Dipartimento di Ingegneria Meccanica Chimica e dei Materiali, Università di Cagliari, via Marengo 2, Cagliari I09123, Italy \\ ${ }^{\ddagger}$ School of Chemistry and EaStChem, University of Edinburgh, King's Buildings, David Brewster Road, Edinburgh EH9 3FJ, U.K. \\ ${ }^{\S}$ Department of Chemistry, Graduate School of Science, and Research Center of Materials Science, Nagoya University, Chikusa-ku, \\ Nagoya 464-8602, Japan
}

\section{Supporting Information}

ABSTRACT: The preparation and characterization of $\mathrm{Ni}(\mathrm{II})$ (1F) and $\mathrm{Cu}(\mathrm{II})(2 \mathrm{~F})$ complexes of the ligand $15,16,17,18,19,20,21,22$-octafluoro-dibenzotetraaza[14]annulene $\left(\mathrm{L}_{\mathrm{F}}\right)$ are here reported. These compounds have been characterized by elemental analysis, mass and UV-vis spectroscopies, single-crystal X-ray diffraction, and computational studies. The effects due to the presence of fluorine atoms have been highlighted by comparison with the analogous complexes of the ligand $\mathrm{L}_{\mathrm{H}}(\mathrm{Ni}: \mathbf{1 H} ; \mathrm{Cu}: \mathbf{2 H})$, which bears hydrogen atoms at the benzenoid rings instead of fluorine. $1 F$ and $2 F$ are isostructural, with the metal ions
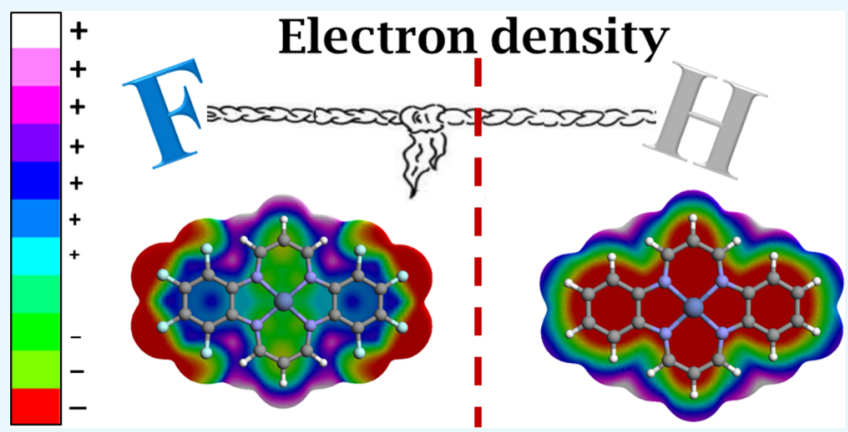
bound to the four nitrogen atoms in a square-planar geometry and where the planar molecules are arranged in a herringbone motif in the crystal lattice. Remarkable differences in the intermolecular interactions between $\mathbf{1 F}$ and $\mathbf{2 F}$ and the corresponding $\mathrm{H}$-complexes are shown by Hirshfeld surface calculations. Moreover, the effects of fluorination on the electronic structures have been investigated by density functional theory (DFT) and time-dependent DFT calculations. The compounds with $\mathrm{L}_{\mathrm{F}}$ and $\mathrm{L}_{\mathrm{H}}$ ligands present corresponding molecular orbitals (MOs) with similar shapes. Furthermore, while the presence of F-atoms lowers the energy of the MOs in comparison with those of the $\mathrm{L}_{\mathrm{H}}$ complexes, it does not remarkably affect the highest occupied molecular orbital (HOMO)-lowest unoccupied molecular orbital (LUMO) and HOMO-LUMO + 1 gaps, in agreement with the UV-vis results.

\section{INTRODUCTION}

Over the last few decades, intense interest has been focused on macrocyclic metal complexes toward their application in many different fields. In particular, among this class of compounds, porphyrins and phthalocyanines $\left(\mathrm{Pc}_{\mathrm{c}}\right.$ ) have been extensively studied and demonstrated as candidates for applications including catalysis, ${ }^{1}$ medicine, ${ }^{2}$ sensors, ${ }^{3}$ and as the active layer(s) in field-effect transistors ${ }^{4}$ and photovoltaic solar cells. ${ }^{5}$ These molecules are characterized by the planarity of the core structure, which allows an extended electron-delocalization due to 22 and $38 \pi$-electrons for the porphyrin and phthalocyanine ligands, respectively. Moreover, the planarity enables an overlap of the $\pi$-orbitals between molecules, which plays a crucial role in achieving good charge transport characteristics. ${ }^{6}$ In addition, the physical and chemical properties (such as magnetism, photoluminescence, absorption, redox potentials) of these macrocycles complexes can be finely tuned by changing the metal ${ }^{6,7}$ and/or the substituents at the periphery of the core. ${ }^{7-14}$ The addition of benzene rings to the phthalocyanine, for instance, causes a red-shift of the intense absorption at the longest wavelength, ${ }^{8}$ whereas a switch from p-type to air-stable n-type semiconductor behavior occurs when the peripheral hydrogen atoms are substituted with fluorines. ${ }^{9,10,14}$ The exchange of a part or all of the $\mathrm{C}-\mathrm{H}$ bonds with $\mathrm{C}-\mathrm{F}$ ones at the outer rim of the macrocyclic ligands also heavily affects the ambient stability of the complexes, ${ }^{9,10}$ as well as their catalytic ${ }^{15-17}$ and therapeutic properties. ${ }^{18}$ Moreover, the presence of fluorine atoms also changes the surface tension, the thermal stability, ${ }^{11}$ and the solubility of the molecules. ${ }^{13}$

The remarkable changes observed in the chemical and physical properties of a molecule when fluorine replaces hydrogen are mainly related to the lower polarizability $\left(\alpha_{\mathrm{D}}\right.$ : 3.76 vs 4.5$)^{19}$ and the higher electronegativity (Pauling scale: 3.98 vs 2.10 ) presented by the halogen atom. For instance, the strong electron-withdrawing capability of fluorine stabilizes the molecular orbitals (MOs). The lowering in energy of the highest occupied molecular orbital (HOMO) makes the molecule more stable versus oxidative degradation, whereas the stabilization of the lowest unoccupied molecular orbital (LUMO) confers to the complex an acceptor capability manifested, in some cases, by the behavior as an air-stable n-

Received: June 25, 2018

Accepted: August 13, 2018

Published: August 29, 2018 
type semiconductor. ${ }^{20-22}$ Furthermore, the fluorination also has great influence on the intermolecular interactions and therefore on the arrangement of the molecules in the solid state, which can additionally affect the colligative properties, such as charge transport. ${ }^{23,24}$

In comparison to other macrocyclic ligands, such as phthalocyanines or porphyrins, the dibenzotetraaza[14]annulenes (Chart 1) and their metal complexes have been

\section{Chart 1}

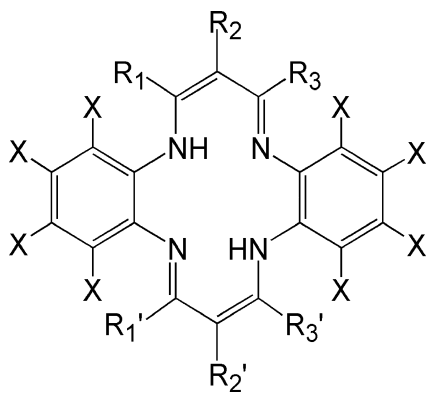

less investigated. ${ }^{25}$ They have been proposed as catalysts, ${ }^{26,27}$ catalase enzyme mimics, ${ }^{28-30}$ materials for recordable optical disks, $^{31}$ and electrical conductors. ${ }^{32}$ Distinct from the aforementioned macrocycles ligands, those belonging to the class of dibenzotetraaza[14]annulenes present a ring formed by 14 atoms; consequently, the core is smaller by about $0.1 \AA$ compared to those of porphyrins. ${ }^{33}$ Furthermore, the macrocycle is less rigid, and the ligands and corresponding complexes can show different conformations depending on the substituents on the 1,3-propanediiminato moieties. In general, when $\mathrm{R}_{1}=\mathrm{R}_{1}{ }^{\prime}=\mathrm{R}_{3}=\mathrm{R}_{3}^{\prime}=\mathrm{X}=\mathrm{H}$ (Chart 1 ) the ligands are planar, ${ }^{33-35}$ whereas if these positions are occupied by morebulky groups, the molecules adopt a "saddle-shaped" conformation $^{26}$ due to the steric interactions of the substituents with the benzenoid rings. This distorted conformation increases the solubility and the chemical reactivity ${ }^{36}$ of these molecules but also influences the crystal packing, reducing the $\pi-\pi$ intermolecular overlaps and thereby hampering good conducting properties in these complexes.

Recently, some of us reported a study on the structural, electronic, and magnetic properties of the complexes of three first row metal +2 ions $(\mathrm{Co}, \mathrm{Ni}(\mathbf{1} \mathbf{H})$, and $\mathrm{Cu}(\mathbf{2} \mathbf{H}))$ with the dibenzotetraaza[14]annulenes ligand (all $\mathrm{R}$ and $\left.\mathrm{X}=\mathrm{H} ; \mathrm{L}_{\mathrm{H}}\right){ }^{37}$ Thin-film electric transport properties were also investigated, showing a p-type semiconductor behavior.

Here, we report the synthesis and characterization of $\mathrm{Ni}$ (II) and $\mathrm{Cu}(\mathrm{II})$ complexes of the ligand $15,16,17,18,19,20,21,22$ octafluoro-dibenzotetraaza[14] annulene $\left(\mathrm{X}=\mathrm{F} ; \mathrm{L}_{\mathrm{F}}\right)$, which are analogues of $\mathrm{L}_{\mathrm{H}}$, bearing fluorine atoms at the benzenoid rings instead of hydrogen. The effects due to this substitution on the crystal and electronic structures are investigated by means of single-crystal X-ray diffraction and density functional theory (DFT) and are highlighted by comparison with the corresponding $\mathrm{L}_{\mathrm{H}}$ complexes. The results of this study shed further light on the effect of fluorination of $\pi$-conjugated systems, which are known to affect both the intramolecular energetics and the intermolecular interactions. The reduced $\pi-\pi$ interactions in the present molecules allow the subtle effects of fluorination on the packing and intermolecular contacts to be observed and are here highlighted by detailed Hirshfeld surface (HS) analysis.

\section{RESULTS AND DISCUSSION}

Synthesis and Crystal Structures. The two complexes were prepared modifying a procedure already reported in the literature, ${ }^{38}$ mixing the perfluorinated ligand 3,4,5,6-tetrafluoro-1,2-phenylenediamine $\left(\mathrm{C}_{6} \mathrm{~F}_{4}\left(\mathrm{NH}_{2}\right)_{2}\right)$ with the corresponding $\mathrm{M}(\mathrm{II})$ acetate salt in a 2:1 methanol/ethanol solution. Other complexes of fluorinated dibenzotetraaza[14]annulene have been previously reported: [Ni(cis-BTDMTAA)] $\left(\mathrm{R}_{1}=\mathrm{R}_{1}{ }^{\prime}=\right.$ methyl; $\mathrm{R}_{3}=\mathrm{R}_{3}{ }^{\prime}=$ trifluoromethyl; Chart 1$)$, [Ni(trans-BTDMTAA $)$ ( $\mathrm{R}_{1}=\mathrm{R}_{3}{ }^{\prime}=$ methyl; $\mathrm{R}_{1}{ }^{\prime}=\mathrm{R}_{3}=$ trifluoromethyl) and [Ni(OFTMTAA)] $\left(\mathrm{R}_{1}=\mathrm{R}_{1}{ }^{\prime}=\mathrm{R}_{3}=\mathrm{R}_{3}{ }^{\prime}=\right.$ methyl; $\mathrm{X}=\mathrm{F}) .^{39}$ These compounds, which were obtained in very low yields $(0.13-0.41 \%)$, were investigated as catalysts for $\mathrm{CO}_{2}$ reduction; no crystal structures are available for these complexes.

Crystals suitable for single-crystal structure determination were grown by sublimation. A summary of crystallographic data is reported in Table 1 . The two complexes $\mathbf{1 F}$ and $2 \mathbf{F}$ are

Table 1. Summary of X-ray Crystallographic Data for 1F and $2 F^{a}$

\begin{tabular}{|c|c|c|}
\hline empirical formula & $\mathrm{C}_{18} \mathrm{H}_{6} \mathrm{~F}_{8} \mathrm{~N}_{4} \mathrm{Ni}$ & $\mathrm{C}_{18} \mathrm{H}_{6} \mathrm{~F}_{8} \mathrm{~N}_{4} \mathrm{Cu}$ \\
\hline formula weight & 488.96 & 493.81 \\
\hline color, habit & orange, prism & orange, prism \\
\hline crystal size, mm & $0.100 \times 0.090 \times 0.070$ & $0.13 \times 0.03 \times 0.03$ \\
\hline crystal system & monoclinic & monoclinic \\
\hline space group & $P 2_{1} / n$ & $P 2_{1} / n$ \\
\hline$a, \AA$ & $9.3936(17)$ & $9.457(6)$ \\
\hline$b, \AA$ & $4.6798(8)$ & $4.715(3)$ \\
\hline$c, \AA$ & $17.703(3)$ & $17.574(11)$ \\
\hline$\beta, \operatorname{deg}$ & $100.4400(19)$ & $100.787(9)$ \\
\hline$V, \AA^{3}$ & $765.3(2)$ & $769.9(8)$ \\
\hline$Z$ & 2 & 2 \\
\hline$T, \mathrm{~K}$ & 123 & 123 \\
\hline$\rho($ calc $), \mathrm{Mg} \mathrm{m}^{-3}$ & 2.122 & 2.130 \\
\hline$\mu, \mathrm{mm}^{-1}$ & 1.3776 & 1.5279 \\
\hline$\theta$ range, deg & $-110.0-70.0$ & $-110.0-70.0$ \\
\hline no. of $\mathrm{rflcn} / \mathrm{unique}$ & $5275 / 1696$ & $5649 / 1757$ \\
\hline GooF & 1.105 & 1.237 \\
\hline$R_{1}$ & 0.0280 & 0.0521 \\
\hline $\mathrm{w} R_{2}$ & 0.0696 & 0.1466 \\
\hline
\end{tabular}

isostructural and crystallize in the monoclinic $P 2_{1} / n$ space group. The molecules in the crystals have a center of symmetry, and half of a molecule is crystallographically independent.

Figure 1 shows the crystal structure of $\mathbf{1 F}$, whereas that of $2 \mathrm{~F}$ is reported in Figure S1. In both cases, the metal ion is bound to the four nitrogen atoms in a square-planar geometry and the molecules are planar (Figure S2). The maximum (average) atomic displacements from the molecular plane (defined by all nonhydrogen atoms) correspond to those of the atoms F4 and are $0.056(0.017)$ and $0.064(0.022) \AA$ for $1 F$ and $2 \mathbf{F}$, respectively. In the case of the unsubstituted complexes, the average atomic deviations from the plane defined by the nonhydrogen atoms in the two crystallographically independent molecules are 0.041 and $0.014 \AA$ for $\mathbf{1 H}$ and 0.024 and $0.040 \AA$ for $2 \mathbf{H}^{35,37}$ A summary of the bond distances and angles is reported in Table 2. The Ni-N (Cu- 


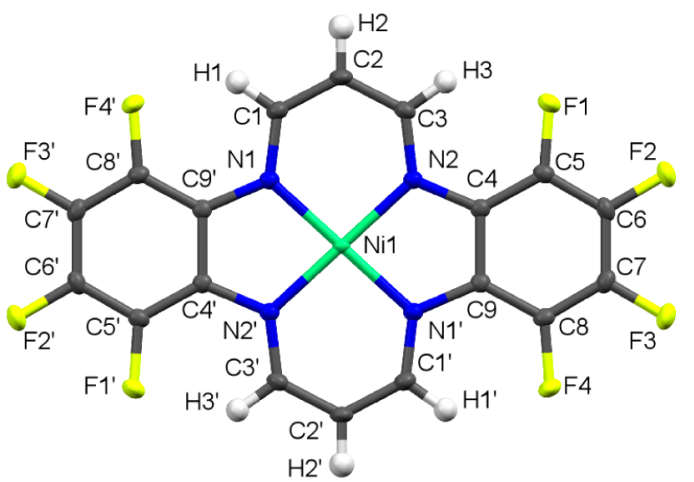

(a)

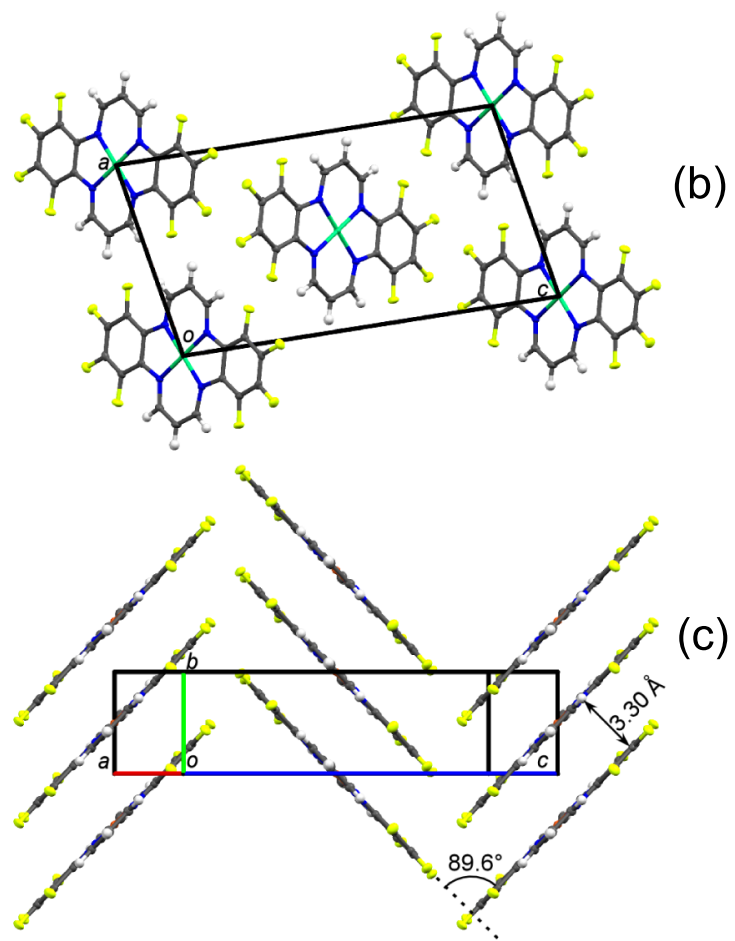

Figure 1. Molecular structure of $\left[\mathrm{Ni}\left(\mathrm{L}_{\mathrm{F}}\right)\right](1 \mathrm{~F})$ with the atomic numbering and thermal ellipsoids at the $50 \%$ probability level (a). Two different projections $(\mathrm{b}, \mathrm{c})$ of the crystal packing of $1 \mathrm{~F}$.

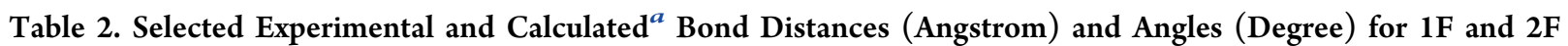

\begin{tabular}{|c|c|c|c|c|c|c|c|}
\hline & \multicolumn{2}{|c|}{ (1) } & \multicolumn{5}{|c|}{ (2) } \\
\hline $\mathrm{Ni}-\mathrm{N} 1$ & $1.8757(14) 1.903$ & $\mathrm{C} 4-\mathrm{C} 5$ & $1.398(2) 1.402$ & $\mathrm{Cu}-\mathrm{N} 1$ & $1.937(3) 1.968$ & $\mathrm{C} 4-\mathrm{C} 5$ & $1.399(5) 1.401$ \\
\hline $\mathrm{Ni}-\mathrm{N} 2$ & $1.8778(13)$ & $\mathrm{C} 5-\mathrm{C} 6$ & $1.373(3) 1.388$ & $\mathrm{Cu}-\mathrm{N} 2$ & $1.938(3)$ & $\mathrm{C} 5-\mathrm{C} 6$ & $1.372(6) 1.388$ \\
\hline $\mathrm{N} 1-\mathrm{C} 1$ & $1.337(2) 1.331$ & $\mathrm{C} 6-\mathrm{C} 7$ & $1.377(2) 1.383$ & $\mathrm{~N} 1-\mathrm{C} 1$ & $1.338(4) 1.330$ & $\mathrm{C} 6-\mathrm{C} 7$ & $1.379(5) 1.383$ \\
\hline $\mathrm{N} 2-\mathrm{C} 3$ & $1.336(2)$ & $\mathrm{C} 7-\mathrm{C} 8$ & $1.374(2)$ & $\mathrm{N} 2-\mathrm{C} 3$ & $1.335(5)$ & $\mathrm{C} 7-\mathrm{C} 8$ & $1.371(5)$ \\
\hline $\mathrm{N} 1-\mathrm{C} 9^{\prime}$ & $1.409(2)$ & $\mathrm{C} 8-\mathrm{C} 9$ & $1.396(3)$ & $\mathrm{N} 1-\mathrm{C} 9^{\prime \prime}$ & $1.413(5)$ & $\mathrm{C} 8-\mathrm{C} 9$ & $1.387(6)$ \\
\hline $\mathrm{N} 2-\mathrm{C} 4$ & $1.407(2) 1.405$ & $\mathrm{~F} 1-\mathrm{C} 5$ & $1.3501(19) 1.351$ & $\mathrm{~N} 2-\mathrm{C} 4$ & $1.404(5) 1.400$ & $\mathrm{~F} 1-\mathrm{C} 5$ & $1.356(4) 1.351$ \\
\hline $\mathrm{C} 1-\mathrm{C} 2$ & $1.381(3) 1.387$ & $\mathrm{~F} 2-\mathrm{C} 6$ & $1.3473(19) 1.337$ & $\mathrm{C} 1-\mathrm{C} 2$ & $1.388(6) 1.395$ & $\mathrm{~F} 2-\mathrm{C} 6$ & $1.342(4) 1.337$ \\
\hline $\mathrm{C} 2-\mathrm{C} 3$ & $1.383(3)$ & F3-C7 & $1.344(2)$ & $\mathrm{C} 2-\mathrm{C} 3$ & $1.392(6)$ & $\mathrm{F} 3-\mathrm{C} 7$ & $1.353(5)$ \\
\hline C4-C9 & $1.418(2) 1.420$ & $\mathrm{~F} 4-\mathrm{C} 8$ & $1.3550(19)$ & $\mathrm{C} 4-\mathrm{C} 9$ & $1.425(5) 1.433$ & $\mathrm{~F} 4-\mathrm{C} 8$ & $1.361(4)$ \\
\hline $\begin{array}{l}\mathrm{N} 1-\mathrm{N} 2{ }^{\prime} \text { (bite } \\
\text { distance) }\end{array}$ & $\begin{array}{l}2.525 \\
2.552\end{array}$ & $\mathrm{~N} 1-\mathrm{N} 2$ & $\begin{array}{l}2.777 \\
2.825\end{array}$ & $\begin{array}{l}\mathrm{N} 1-\mathrm{N}^{\prime} \text { (bite } \\
\text { distance) }\end{array}$ & $\begin{array}{l}2.592 \\
2.618\end{array}$ & $\mathrm{~N} 1-\mathrm{N} 2$ & 2.8812 .939 \\
\hline $\mathrm{N} 1-\mathrm{Ni}-\mathrm{N1}{ }^{\prime}$ & $180.00(8) 180.00$ & $\mathrm{C} 1-\mathrm{C} 2-\mathrm{C} 3$ & $\begin{array}{c}125.23(15) \\
125.32\end{array}$ & $\mathrm{~N} 1-\mathrm{Cu}-\mathrm{N} 1^{\prime \prime}$ & $\begin{array}{l}180.00(18) \\
180.00\end{array}$ & $\mathrm{C} 1-\mathrm{C} 2-\mathrm{C} 3$ & $\begin{array}{r}127.8(3) \\
128.08\end{array}$ \\
\hline $\mathrm{N} 1-\mathrm{Ni}-\mathrm{N} 2$ & $95.43(6) 95.82$ & $\mathrm{~N} 2-\mathrm{C} 3-\mathrm{C} 2$ & $124.22(16)$ & $\mathrm{N} 1-\mathrm{Cu}-\mathrm{N} 2$ & $96.06(13) 96.60$ & $\mathrm{~N} 2-\mathrm{C} 3-\mathrm{C} 2$ & $124.3(3)$ \\
\hline $\mathrm{N} 1-\mathrm{Ni}-\mathrm{N} 2^{\prime}$ & $84.57(6) 84.18$ & $\mathrm{Ni}-\mathrm{N} 2-\mathrm{C} 4$ & $\begin{array}{c}114.56(10) \\
114.17\end{array}$ & $\mathrm{~N} 1-\mathrm{Cu}-\mathrm{N} 2^{\prime \prime}$ & $83.94(13) 83.40$ & $\mathrm{Cu}-\mathrm{N} 2-\mathrm{C} 4$ & $\begin{array}{r}113.7(2) \\
113.25\end{array}$ \\
\hline $\mathrm{Ni}-\mathrm{N} 1-\mathrm{C} 1$ & $\begin{array}{l}125.29(12) \\
124.33\end{array}$ & $\mathrm{~N} 2-\mathrm{C} 4-\mathrm{C} 9$ & $\begin{array}{c}113.15(14) \\
113.74\end{array}$ & $\mathrm{Cu}-\mathrm{N} 1-\mathrm{C} 1$ & $123.7(3) 122.37$ & $\mathrm{~N} 2-\mathrm{C} 4-\mathrm{C} 9$ & $\begin{array}{r}114.6(3) \\
115.05\end{array}$ \\
\hline $\mathrm{Ni}-\mathrm{N} 2-\mathrm{C} 3$ & $125.40(12)$ & $\mathrm{N1}^{\prime}-\mathrm{C} 9-\mathrm{C} 4$ & $113.15(15)$ & $\mathrm{Cu}-\mathrm{N} 2-\mathrm{C} 3$ & $123.7(3)$ & $\mathrm{N} 1 "-\mathrm{C} 9-\mathrm{C} 4$ & $114.3(3)$ \\
\hline $\mathrm{N} 1-\mathrm{C} 1-\mathrm{C} 2$ & $\begin{array}{c}124.41(17) \\
125.10\end{array}$ & $\mathrm{Ni}-\mathrm{N} 1-\mathrm{C} 9^{\prime}$ & $114.56(10)$ & $\mathrm{N} 1-\mathrm{C} 1-\mathrm{C} 2$ & $124.4(4) 125.32$ & $\mathrm{Cu}-\mathrm{N} 1-\mathrm{C} 9^{\prime \prime}$ & $113.5(2)$ \\
\hline
\end{tabular}

$\mathrm{N})$ distances are $1.876(1)$ and $1.878(1) \AA(1.937(3)$ and $1.938(3) \AA$ ), while the average of $\mathrm{N}-\mathrm{C}$ bond lengths is 1.336 $(1.336 \AA$ for $2 \mathrm{~F})$ and $1.408 \AA$ (2F: $1.408 \AA)$ for the 1,3propanediiminato and benzenoid moieties, respectively, suggesting a double bond character more pronounced for the former one. Moreover, the $\mathrm{N}-\mathrm{C}$ bond distances, as well as the $\mathrm{C}-\mathrm{C}$ ones in the propanediiminato linkages, are pairwise very similar, suggesting a lack of single-double bond alternation and thus indicating a $\pi$-delocalization within these fragments. Similar results were found also for the unsubstituted free ligand $^{40}$ and complexes. ${ }^{37}$ The bite angles $(\mathrm{N}-\mathrm{M}-\mathrm{N})$ related to the phenylenediamino moieties are $84.57(6)$ and $83.94(13)^{\circ}$ for $\mathbf{1 F}$ and $\mathbf{2 F}$, respectively; these values are slightly smaller than those found for $\mathbf{1 H}$ and $\mathbf{2} \mathbf{H}^{35,37}$

The complexes pack forming columns perpendicular to the ac plane, with alternating orientation of the molecules along the planes (101) and with the same orientation parallel to the $a b$ and $b c$ planes, conferring a herringbone arrangement to the crystal packing (Figures 1 and S3). The distances between adjacent molecules within a column are 3.30 A for $\mathbf{1 F}$ and 3.27 

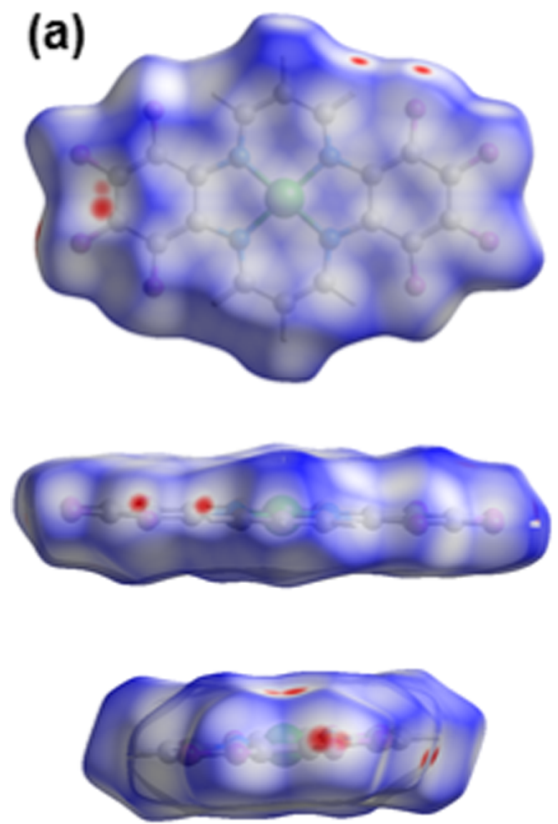

$1 F$
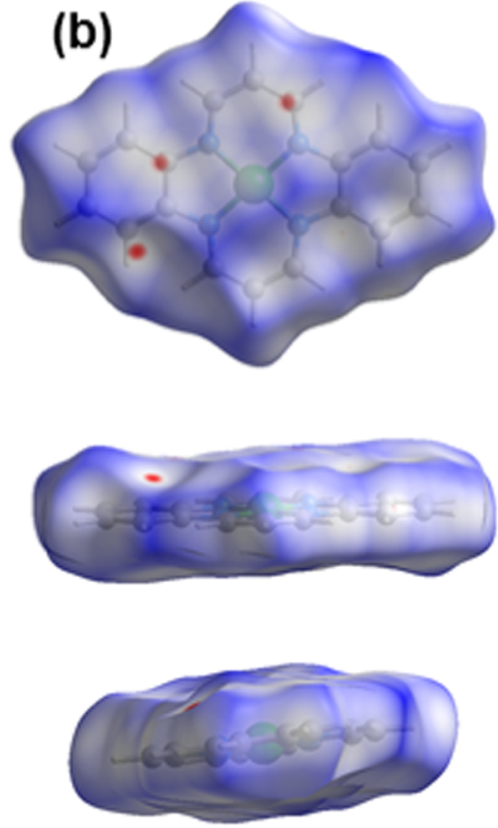

1H
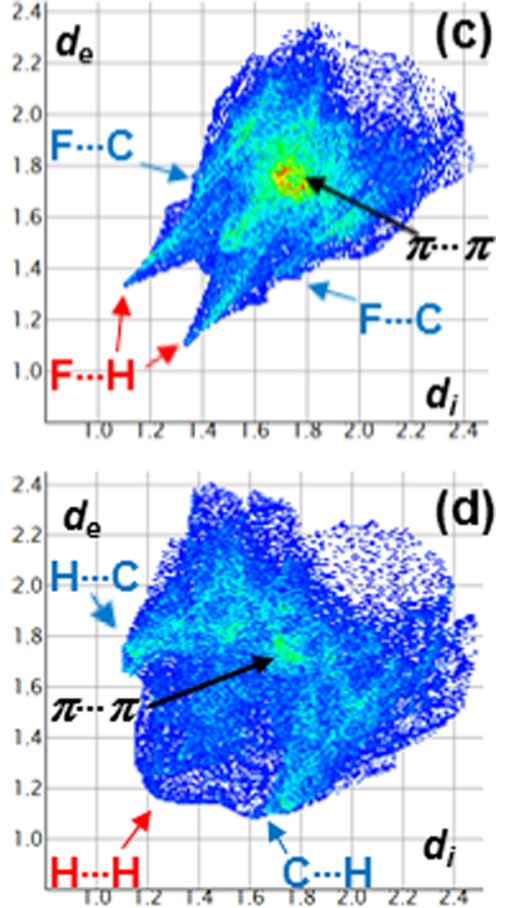

Figure 2. Hirshfeld surfaces for $\mathbf{1 F}(\mathrm{a})$ and $\mathbf{1 H}(\mathrm{b})$ and the corresponding fingerprint plots (c, d).

$\AA$ for $2 \mathrm{~F}$, whereas the angles defined by two molecules differently oriented are 89.6 and $87.8^{\circ}$ for the $\mathrm{Ni}$ and $\mathrm{Cu}$ complexes, respectively. The analogous hydrogenated compounds show slightly shorter corresponding interplanar distances (3.295 $\AA$ for nickel complex and $3.238 \AA$ for the copper one). Moreover, although $\mathbf{1 H}$ and $\mathbf{2 H}$ also pack with a herringbone-like arrangement, the motif is different from that described above for the fluorinated complexes. Indeed, two different herringbone arrangements alternating along $a$ are present in the crystal structures, one for each crystallographically independent molecule (Figure S4). The angle formed by the molecules of the asymmetric unit in the nickel (copper) complex is $52.16\left(52.77^{\circ}\right)$, while those between molecules of differently oriented columns within planes parallel to the $b c$ one are 78.14 and $78.29^{\circ}\left(78.15\right.$ and $\left.77.81^{\circ}\right)$. Distinct from $\mathbf{1} \mathbf{H}^{35,37}$ no distances shorter than the sum of van der Waals (vdW) radii are observed between molecules within a stack for 1F, whereas four C…C contacts (3.399 $\AA$ ) per molecule exist in 2F. F-H (2.533 and $2.670 \AA)$ and F-C (3.056 and $3.114 \AA$ ) short contacts are present between a molecule and its neighbors in the adjacent columns (Figure S5). Furthermore, as shown in Figures S6 and S7, the crystal structures of unsubstituted and fluorinated compounds differ also in the overlap between neighbor molecules, which is markedly more extended in the case of 1F. However, considering the shorter distance between the molecular planes in $\mathbf{1 H}$, in addition to the presence of C...C contacts $(3.33 \AA)$, which seems to suggest a more favorable orbital overlap, stronger $\pi-\pi$ interactions are expected for $\mathbf{1 H}$ (see below the UV-vis measurements discussion).

Hirshfeld Surface Analysis. Hirshfeld surface (HS) $)^{41-43}$ studies have been performed to investigate the effect of fluorination on the solid-state interactions. The HSs of 1F (a) and $\mathbf{1 H}$ (b) mapped with the normalized contact distances $\left(d_{\text {norm }}\right)^{42}$ are reported in Figure 2 (the corresponding copper complexes present similar results). The red, white, and blue colors represent contact distances that are, respectively, shorter, identical, and longer than the sum of the vdW radii (for a more accurate definition of $d_{\text {norm; }}$ see the Supporting Information (SI)); therefore, the red spots on the HSs correspond to the intermolecular short contacts mentioned above (see also Figure S8). The differences in the number and position of these spots between the HSs of $1 \mathrm{~F}$ and $1 \mathrm{H}$ reflect the distinctions in their intermolecular interactions. These differences in the intermolecular contacts are clearly highlighted by a comparison between the Hirshfeld fingerprints plots (FPs) ${ }^{44,45}$ shown in Figure $2 \mathrm{c}$,d, which provide an overall two-dimensional representation of the interactions occurring between the molecules in the crystal (for details about the construction of the FPs; see the SI or ref 44). The FPs of $\mathbf{1 F}$ and $\mathbf{1 H}$ present remarkable differences. In particular, the fingerprints of the fluorinated complex (Figure 2c) display two sharp peaks in the bottom left region of the plot, which are related to the $\mathrm{H} \cdots \mathrm{F}$ interactions in addition to two small regions due to the F...C contacts (see also Figure S9). As expected, different types of intermolecular contacts appear in the FP of $\mathbf{1 H}$ (Figure $2 \mathrm{~d}$ ), namely, weak $\mathrm{H} \cdots \mathrm{H}$ interactions in the bottom left part of the plot and the $\mathrm{C} \cdots \mathrm{H}$ ones in the two regions around the points corresponding to $d_{\mathrm{e}}=1.78 \AA$ and $d_{\mathrm{i}}$ $=1.1 \AA$, and vice versa (see Figures S10 and S11). The differences in the intermolecular overlap mentioned above show up in the region roughly in the center of the plot $\left(d_{\mathrm{e}}\right.$ and $d_{\mathrm{i}} \sim 1.8-2.0 \AA$ ) , where a larger interaction is seen for $1 \mathrm{~F}$, compared to $1 \mathbf{H}$, in accordance with a more extended $\pi-\pi$ overlap in the case of $1 \mathrm{~F}$. These findings are also highlighted by the curvedness $(C)$ mapped onto the HS (Figures S12S15). The fingerprint analysis also allows a quantification of the contributions from the different types of intermolecular contacts to the HS. Figure S16 shows a comparison between the percentage contributions for fluorinated and hydrogenated complexes. One can notice that the variation of the metal ion does not significantly affect the percentages, whereas huge 
differences are observed varying the ligand. Indeed, in $\mathbf{1 H}$ and $\mathbf{2 H}$, the largest contribution is by far that related to the $\mathrm{H} \cdots \mathrm{H}$ interactions (42.4 and 41.2\%, respectively); furthermore, considering also the $\mathrm{H} \cdots \mathrm{C}$ contacts $(15.0 \%$ for $\mathbf{1 H}$ and $15.4 \% 2 \mathrm{H}$ ), more than half of the HS is due to contributions involving the hydrogen atoms of the molecule. The effects of fluorine substitution on the intermolecular interactions are confirmed by the percentage of contributions involving the halogen atoms (F...X; X $=F, C, H)$ in $\mathbf{1 F}$ and $\mathbf{2 F}$, which are $\approx 41 \%$. Those related to $\mathrm{C} \cdots \mathrm{X}$ and $\mathrm{H} \cdots \mathrm{X}$ are approximately 18 and $21 \%$, respectively.

UV-Vis Measurements. UV-vis spectroscopic measurements on the investigated complexes were performed in dimethylformamide (DMF) solution (Figure 3). An intense

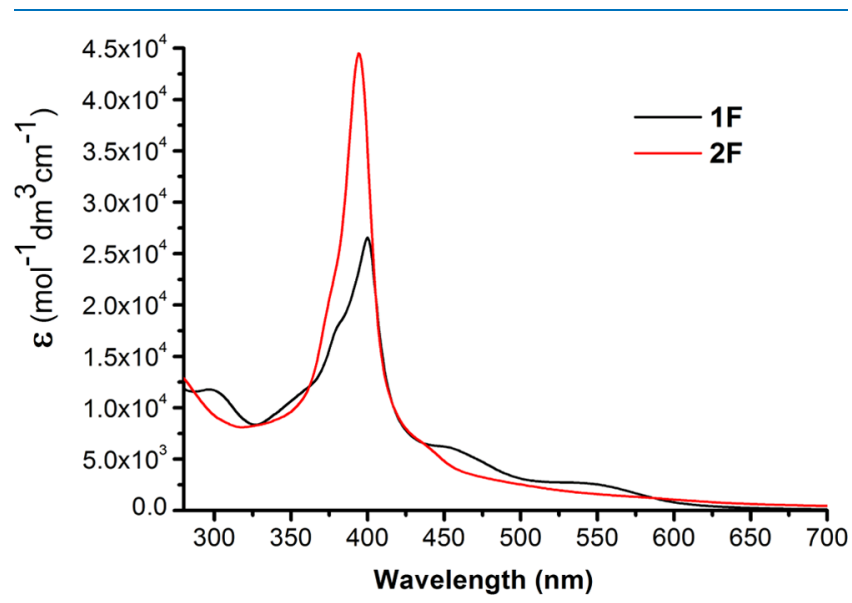

Figure 3. UV-vis spectra in DMF solution of $1 \mathrm{~F}$ and $2 \mathrm{~F}$ complexes.

absorption is present in the visible region at $400 \mathrm{~nm}$ for the nickel complex and at $394 \mathrm{~nm}$ for the copper one, with molar extinction coefficients of $2.66 \times 10^{4}$ and $4.45 \times 10^{4} \mathrm{dm}^{3} \mathrm{~mol}^{-1}$ $\mathrm{cm}^{-1}$ for $\mathbf{1 F}$ and $2 \mathrm{~F}$, respectively. By time-dependent (TD)DFT calculations (vide infra), these bands have been assigned mainly $(77 \%)$ to a $\mathrm{HOMO} \rightarrow \mathrm{LUMO}+1$ transition for $\mathbf{1 F}$, whereas in the case of $\mathbf{2 F}$, several transitions contribute to the absorption. The wavelengths corresponding to the band maxima are quite similar to those observed in the case of unsubstituted complexes, which fall at $425 \mathrm{~nm}$ for the $\mathbf{1 H}$ and $406 \mathrm{~nm}$ in the $\mathbf{2 H}$ case (see Figure S17). Furthermore, less intense bands are present at lower ( 540 and $450 \mathrm{~nm}$ for $1 \mathrm{~F}$ and $440 \mathrm{~nm}$ for $2 \mathrm{~F}$ ) as well as at higher energies (297, 350, and 380 $\mathrm{nm}$ for $1 \mathrm{~F}$ and 280 and $370 \mathrm{~nm}$ for $2 \mathrm{~F}$ ). A comparison between the diffuse reflectance spectra is reported in Figure S18. As can be seen, all three compounds investigated show an additional absorption at red and near-infrared (NIR) wavelengths. The intensity and the extension of these bands increase in the order $\mathbf{1 F}<\mathbf{2 F}<\mathbf{1 H}$; this trend might be explained taking into account the solid-state interactions, in particular those involving $\pi$-systems. Indeed, as discussed above, although less extended in comparison with those in fluorinated compounds, the $\pi-\pi$ interactions are stronger in the unsubstituted complex. Interesting, especially in the $\mathbf{1 H}$ case, the solid-state absorption covers continuously a part of the electromagnetic spectrum, which encompasses the whole visible region, as well as part of the ultraviolet and the NIR. This behavior is characteristic of so-called "black absorbers", which are investigated for photovoltaic applications. ${ }^{46}$

DFT Calculations. With the aim of investigating the effect induced by the fluorination on the electronic structures of the complexes, computational investigation by DFT methods was performed. The optimized geometries for compounds $\mathbf{I F}$ and 2F, calculated in the gas phase, are reported in Figures S20 and S21. Differences in the planarity are observed depending on the origin of the input file. Indeed, if the optimization starts from the crystal data, the calculated structures are planar, in accordance with those founded by single-crystal X-ray diffraction. However, calculations inputted with the file obtained from ArgusLab program ${ }^{47}$ lead to optimized geometries exhibiting a saddle-shaped conformation, in agreement with the findings reported for $\mathbf{1 H}$ and $\mathbf{2 H}$ (Figure S22). ${ }^{37}$ The calculated total energies of the corresponding conformers are very similar (see Figures S20 and S21), suggesting that the deformations from planarity do not have important electronic effects. The almost equivalence in the energies despite the different conformations might be relatable to the negligible $\pi$-electron conjugation between the phenyl rings and the $\mathrm{N}-(\mathrm{CH})_{3}-\mathrm{N}$ groups, where the $\pi$-delocalization is not extended all over the cycle but restricted within the
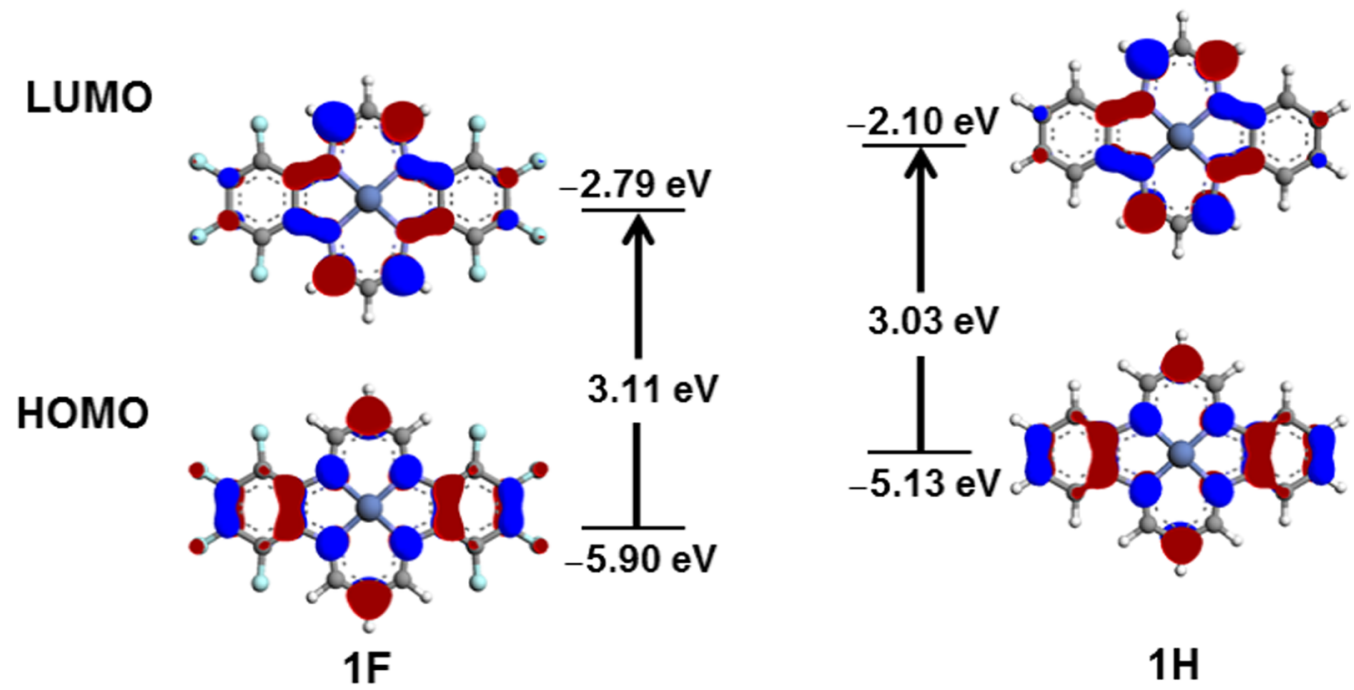

$1 \mathrm{H}$

Figure 4. Frontier orbitals of $1 \mathrm{~F}$ and $1 \mathrm{H}$ calculated by DFT methods in the gas phase and plotted with a contour value of 0.040 . 


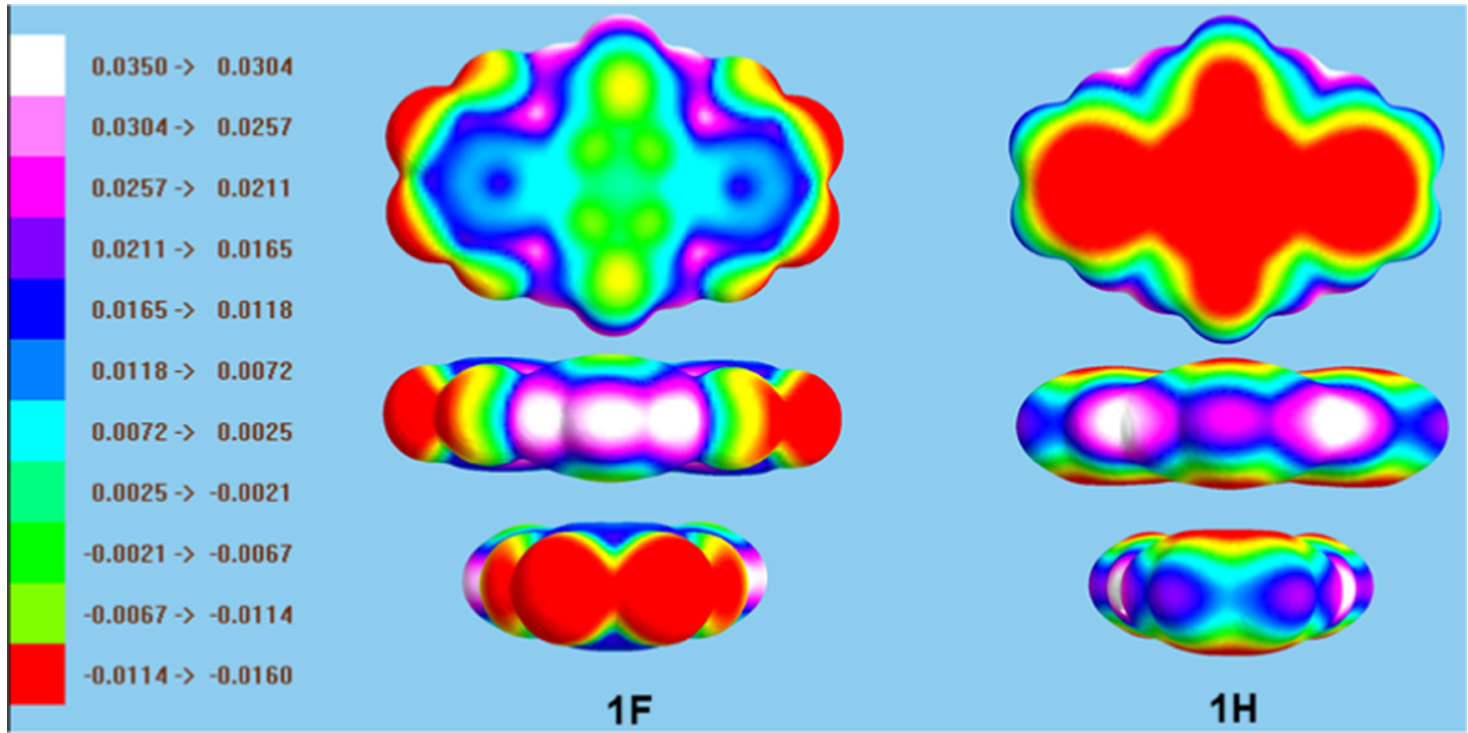

Figure 5. EPs mapped on electron density isosurfaces for $\mathbf{1 F}$ and $\mathbf{1 H}$ calculated by DFT (contour plot 0.001 ). The colors are mapped according to the electrostatic potential at the point in space on the isosurface.

propane-1,3-diiminato and benzenoid fragments, ${ }^{25}$ in agreement with the antiaromaticity ( $4 n \pi$-electrons) of these ligands.

The calculated bond distances and angles for the planar conformation are in very good agreement with the experimental ones (Table 2). Similar results (see Table S1) were found also in the case of the bent geometry except, as expected, for the angle $\mathrm{C} 2-\mathrm{Ni}-\mathrm{C}_{2}$, which is of 180.00 and $164.41^{\circ}$ in the planar and saddle-shaped conformation, respectively.

The frontier orbitals (FOs) calculated for $\mathbf{1 F}$ and $\mathbf{1 H}$ are depicted in Figure 4 (see also Tables S2 and S3). As one can see, the fluorination does not markedly affect the overall shape of the FOs. The HOMO and LUMO are $\pi$-type orbitals, involving atoms from both types of fragment of the ligand. The main differences between $\mathbf{1 F}$ and $\mathbf{1 H}$ are seen in the distinct contributions from the substituent at the benzene rings (2-5\% for $\mathbf{1 F}$ and 0 for $\mathbf{1 H}$ ) (see Tables S4 and S5). As far as the other atoms are concerned, the propane-1,3-diiminato chelate rings constitute the majority of the FOs.

A more sizeable effect of the fluorination is seen in the energy of the MOs, in particular both HOMO and LUMO of $1 F$ are stabilized by about $0.70 \mathrm{eV}$ in comparison with the corresponding $1 \mathrm{H}$ orbitals, whereas the LUMO +1 orbital is lowered in energy by $0.54 \mathrm{eV}$. As a consequence, comparable HOMO-LUMO and HOMO-LUMO + 1 gaps are expected for halogenated and unsubstituted complexes, consistent with the experimental UV-vis spectra. Similar findings were also observed for the compounds $\mathbf{2 F}$ and $\mathbf{2 H}$ (Tables S6-S11). Furthermore, a comparison between the FOs of analogous complexes with different metal ions highlights that their energy levels are almost unaffected by changing the central atom (Table S12), in accord with the negligible metal contribution. Stabilization effects close to those found for $\mathbf{1}$ and $\mathbf{2}$ were also observed with $\mathrm{CuPc}$ and the analogous perfluorinated complex $\left(\mathrm{F}_{16} \mathrm{CuPc}\right){ }^{22}$ As already mentioned in the Introduction, the effect of the fluorination on the electronic structure of these complexes is related to the electronegativity of $\mathrm{F}$, which confers on this element a strong negative inductive effect $\left(\sigma_{\mathrm{I}}=\right.$ $0.51) .^{24,48}$ Furthermore, fluorine also shows positive mesomeric effect $\left(\sigma_{\mathrm{R}}=-0.34\right) .{ }^{24,48}$ Both of these factors affect the electronic structure, as well as the intermolecular interactions. $^{24}$

Electrostatic potentials (EPs) mapped onto the electron density, as depicted in Figures 5 and S23, also highlight the fluorination effect in the investigated complexes. The electronwithdrawing capability of the halogen atoms indeed pulls the electron density from both types of rings to the periphery of the molecule, causing a remarkable change in the EP distribution. This redistribution toward the fluorine atoms is particularly noticeable in the case of the $\pi$-cloud on the benzene rings, which show negative EPs in $\mathbf{1 H}$ and positive EPs in 1F. Similar effects on the electron density distribution were reported for phthalocyanine complexes for which the substitution with electron-withdrawing groups causes a decrease of electron density in the inner ring $\pi$-system and may induce the switching from p-type to n-type semiconductor behavior. ${ }^{14}$ As expected, these findings are in agreement with the observed intermolecular interactions and confirm the role played by the fluorine atoms in the crystal structures of these compounds. Indeed, in 1F, the fluorine atoms (negative EP) show short contacts with $\mathrm{H}$ and $\mathrm{C}$ at the benzene rings (positive EP), whereas the unsubstituted complex presents interactions involving hydrogen atoms and the partially negatively charged aromatic carbons.

Moreover, looking closer at the electron density distribution at the fluorine atoms, it can be seen that there is no $\sigma$-hole (region positively charged at the opposite side of the $\mathrm{C}-\mathrm{F}$ bond) that is necessary for the occurrence of halogen bonds. ${ }^{49}$ However, similar calculations performed on the analogous chlorinated complex predict the presence of the $\sigma$-hole at the halogen atoms (see Figure S24), suggesting possible different solid-state interactions.

\section{CONCLUSIONS}

Complexes 1F and 2F have been prepared and characterized by elemental analysis, mass and UV-vis spectroscopies, singlecrystal X-ray diffraction, and computational studies. The effects due to the presence of fluorine atoms have been highlighted by comparison with the analogous complexes $\mathbf{1 H}$ and $2 \mathbf{H}$, which bear hydrogen atoms at the benzenoid rings instead of 
fluorines. $1 \mathrm{~F}$ and $2 \mathrm{~F}$ are isostructural with the metal ion bound to the four nitrogen atoms in a square-planar geometry, in planar molecules arranged in a herringbone motif in the crystal packing. Remarkable differences in the intermolecular interactions between $\mathbf{1 F}$ and $\mathbf{2 F}$ and the corresponding $\mathrm{H}$ complexes are shown by HS calculations. In particular, the fingerprints of the fluorinated complexes show two sharp peaks related to the $\mathrm{H} \cdots \mathrm{F}$ interactions, in addition to two small regions due to the F...C contacts; on the whole, the percentage of contributions involving halogen atoms in $\mathbf{1 F}$ and $2 \mathrm{~F}$ is $\approx 68 \%$. The $\mathrm{HS}$ of the $\mathrm{L}_{\mathrm{H}}$ ligand is instead dominated by $\mathrm{H} \cdots \mathrm{H}$ $(\approx 42 \%), \mathrm{H} \cdots \mathrm{C}(\approx 15 \%)$, and $\mathrm{C} \cdots \mathrm{H}(\approx 21 \%)$ interactions. DFT optimized geometries are in very good agreement with the experimental data. The calculated MOs of the complexes with $\mathrm{L}_{\mathrm{F}}$ and $\mathrm{L}_{\mathrm{H}}$ present similar shapes, with HOMOs and LUMOs that are $\pi$-type orbitals, involving atoms from both types of fragment in the ligands. Furthermore, although the presence of F-atoms lowers the energy of the MOs in comparison with those of the $\mathrm{L}_{\mathrm{H}}$ complexes, it does not affect the HOMOLUMO and HOMO-LUMO + 1 gaps, in agreement with the $\mathrm{UV}-\mathrm{vis}$ results.

\section{EXPERIMENTAL SECTION}

All the reagents and solvents were purchased from Aldrich and used without further purification. The ligand 3,4,5,6-tetrafluoro-1,2-phenylenediamine $\left(\mathrm{C}_{6} \mathrm{~F}_{4}\left(\mathrm{NH}_{2}\right)_{2}\right)$ was prepared as previously reported in ref 50 . The reagent 2-propynal (2propiolaldehyde) was synthesized in accordance with the procedure reported by Sauer et al. ${ }^{51}$

Preparation. $\left[\mathrm{Ni}\left(L_{F}\right)\right]$ (1F). Synthesis: Complex 1 was prepared by adapting the procedure already reported in the literature for $1 \mathrm{H}^{52}$ First, $216 \mathrm{mg}(4.0 \mathrm{mmol})$ of 2 propiolaldehyde was dissolved in $5.0 \mathrm{~mL}$ of ethanol and added to a solution of $720 \mathrm{mg}(4.0 \mathrm{mmol})$ of $\mathrm{C}_{6} \mathrm{~F}_{4}\left(\mathrm{NH}_{2}\right)_{2}$ in $15.0 \mathrm{~mL}$ of methanol/ethanol 2:1. The resulting solution was warmed to $50{ }^{\circ} \mathrm{C}$, and then $498 \mathrm{mg}(2.0 \mathrm{mmol})$ of $\left[\mathrm{Ni}(\text { acetate })_{2}\right] \cdot 4 \mathrm{H}_{2} \mathrm{O}$ in $10.0 \mathrm{~mL}$ of warm methanol was added dropwise. The mixture was refluxed under stirring for 45 min and then cooled to room temperature. The solid was collected by filtration, washed three times with methanol, and dried in air. Next, $310 \mathrm{mg}$ (yield $0.63 \mathrm{mmol} ; 31 \%$ ) of product was obtained. Analytical results are in accordance with the formula $\left[\mathrm{Ni}\left(\mathrm{L}_{\mathrm{F}}\right)\right]$. Elemental analysis: calculated for $\mathrm{C}_{18} \mathrm{H}_{6} \mathrm{~F}_{8} \mathrm{~N}_{4} \mathrm{Ni}$ (488.95): $\mathrm{C} 44.22, \mathrm{H} 1.24, \mathrm{~N} \mathrm{11.46;} \mathrm{found:} \mathrm{C}$ 44.26, H 1.25, N 11.37. MS (EI): $m / z$ (\%) 488.0 (100.00\%) $\left[\mathrm{M}^{+}\right]$. UV-vis (in DMF; $\lambda$, nm $\left(\varepsilon, \mathrm{dm}^{3} \mathrm{~mol}^{-1} \mathrm{~cm}^{-1}\right)$ ): 297 $\left(1.18 \times 10^{4}\right)$; 350, sh; 380, sh; $400\left(2.66 \times 10^{4}\right) ; 450$, sh; 540, sh.

$\left[C U\left(L_{F}\right)\right]$ (2F). Synthesis: Complex 2F was prepared following the procedure reported above for the analogous nickel complex using $218 \mathrm{mg}(4.0 \mathrm{mmol})$ of 2-propiolaldehyde, $721 \mathrm{mg}(4.0 \mathrm{mmol})$ of $\mathrm{C}_{6} \mathrm{~F}_{4}\left(\mathrm{NH}_{2}\right)_{2}$, and $399.6 \mathrm{mg}(2.0 \mathrm{mmol})$ of $\left[\mathrm{Cu}(\text { acetate })_{2}\right] \cdot \mathrm{H}_{2} \mathrm{O}$. First, $295 \mathrm{mg}$ (yield $0.59 \mathrm{mmol} ; 29 \%$ ) of product was obtained. Analytical results are in accordance with the formula $\left[\mathrm{Cu}\left(\mathrm{L}_{\mathrm{F}}\right)\right]$. Elemental analysis: calculated for $\mathrm{C}_{18} \mathrm{H}_{6} \mathrm{~F}_{8} \mathrm{~N}_{4} \mathrm{Cu}$ (493.80): C 44.22, $\mathrm{H}$ 1.24, N 11.46; found: $\mathrm{C}$ 43.59, H 1.31, N 11.28. MS (EI): $m / z$ (\%) 493.0 (100.00\%) $\left[\mathrm{M}^{+}\right]$. UV-vis (in DMF; $\left.\lambda, \mathrm{nm}\left(\varepsilon, \mathrm{dm}^{3} \mathrm{~mol}^{-1} \mathrm{~cm}^{-1}\right)\right): 280$, sh; 370 , sh; $394\left(4.45 \times 10^{4}\right)$; 440, sh.

Elemental analyses were performed with a Carlo Erba CE1108 Elemental Analyser. MS were recorded on a ThermoElectron MAT 900 by an electron impact (EI) ionization technique. The UV-vis-near-IR spectra were measured with a Jasco V-670 spectrophotometer equipped with a diffuse reflectance accessory. Solution measurements (DMF) were recorded using a quartz cell of path length $1 \mathrm{~cm}$, while diffuse reflection measurements were performed on $\mathrm{KBr}$ pellets.

Single-Crystal X-ray Crystallography. All measurements were made on a Rigaku Saturn CCD area detector with graphite monochromated Mo K $\alpha$ radiation $(\lambda=0.71073 \AA)$ at $123 \mathrm{~K}$. Data were collected and processed using CrystalClear (Rigaku). ${ }^{52}$ The structures were solved by direct methods ${ }^{53}$ and expanded using Fourier techniques. ${ }^{54}$ The nonhydrogen atoms were refined anisotropically. Hydrogen atoms were refined using the riding model. All calculations were performed using the CrystalStructure ${ }^{55}$ crystallographic software package except for refinement, which was performed using SHELXL97. ${ }^{56}$ Crystallographic data of $\mathbf{1 F}$ and $\mathbf{2 F}$ are given in Table 1 ; more details about single-crystal measurements are available in the Supporting Information (SI).

DFT Calculations. Ground-state electronic structure calculations were performed as previously reported ${ }^{57}$ at the DFT $^{58}$ level employing the GAUSSIAN $09^{59}$ software package and using B3LYP as functional ${ }^{60,61}$ and the valence triple- $\zeta 6$ $311+\mathrm{G}(\mathrm{d}, \mathrm{p})^{62}$ as the basis set. The ground-state geometries were optimized both in the vacuum and in a DMF-simulated electric field; frequencies analyses were done to verify that the optimized geometries are true minima. The 20 lowest singlet excited states of the closed shell complexes $1 \mathbf{H}$ and $1 \mathrm{~F}$ and the 40 lowest excited states of the open shell complexes $2 \mathbf{H}$ and $2 \mathrm{~F}$ were calculated within the time-dependent DFT calculations using the formalism as implemented in Gaussian. ${ }^{59}$ More details are given in the SI.

Hirshfeld Surface Analysis. The Hirshfeld surface (HS) analysis $^{41}$ was performed as reported in ref 63 and further described in the SI; all the calculations on the HS surface and its properties were performed by the CrystalExplorer 3.1 program. $^{64}$

\section{ASSOCIATED CONTENT}

\section{S Supporting Information}

The Supporting Information is available free of charge on the ACS Publications website at DOI: 10.1021/acsomega.8b01442.

X-ray crystal structures (Figures S1-S7); Hirshfeld surface analysis (Figures S8-S16); UV-vis-NIR spectra (Figures S17-S19); DFT calculations: geometry-optimized structures (Figures S20-S22); calculated bond distances and angles (Table S1); shape, energy, and composition of calculated MOs (Tables S2-S11); electrostatic potential (Figures S23 and S24); TD-DFT calculations (Figures S25 and S26, Tables S12 and S13); calculated spin density (Figures S27 and S28) (PDF) CCDC deposition numbers: 1850561 (1F) and 1850562 (2F) (CIF)

Hirshfeld surface of complex $\mathbf{1 F}(\mathrm{AVI})$

\section{AUTHOR INFORMATION}

\section{Corresponding Author}

*E-mail: pilialuc@unica.it.

ORCID

Luca Pilia: 0000-0001-8753-7094

Kunio Awaga: 0000-0002-2193-0747

Neil Robertson: 0000-0002-9230-6124 


\section{Present Addresses}

"Dipartimento di Ingegneria Meccanica Chimica e dei Materiali, Università di Cagliari, via Marengo 2, I09123 Cagliari, Italy (L.P.).

${ }^{\perp}$ Institut für Physik, Institut für Chemie \& IRIS Adlershof AG Hybride Bauelemente (Hybrid Devices Group), HumboldtUniversität zu Berlin, Brook-Taylor-Straße 6, 12489 Berlin, Germany (S.D.).

\section{Notes}

The authors declare no competing financial interest.

\section{ACKNOWLEDGMENTS}

L.P. thanks the FP-7 PEOPLE-Marie Curie Research Program IEF (contract number: PIEF-GA-2009-252273) and the Università degli Studi di Cagliari for the financial support. Dr. Francesca Mocci is kindly acknowledged for providing the computing facility. K.A. acknowledges the financial support of a Grant-in-Aid for Scientific Research from the Ministry of Education, Culture, Sports, Science, and Technology of Japan (MEXT).

\section{REFERENCES}

(1) (a) Che, C.-M.; Lo, V. K.-Y.; Zhou, C.-Y.; Huang, J.-S. Selective functionalisation of saturated $\mathrm{C}-\mathrm{H}$ bonds with metalloporphyrin catalysts. Chem. Soc. Rev. 2011, 40, 1950-1975. (b) Rybicka-Jasińska, K.; Shan, W.; Zawada, K.; Kadish, K. M.; Gryko, D. Porphyrins as Photoredox Catalysts: Experimental and Theoretical Studies. J. Am. Chem. Soc. 2016, 138, 15451-15458. (c) Nakazono, T.; Parent, A. R.; Sakai, K. Cobalt porphyrins as homogeneous catalysts for water oxidation. Chem. Commun. 2013, 49, 6325-6327.

(2) (a) Handbook of Porphyrin Science Applications with Applications to Chemistry, Physics, Materials Science, Engineering; Biology and Medicine; Ferreira, G. C.; Kadish, K.; Smith, K. M.; Guilard, R., Eds.; World Scientific Publishing Co. Pte. Ltd.: Singapore, 2014; Vol. 27, 29. (b) The Porphyrin Handbook-Applications: Past, Present and Future; Kadish, K.; Smith, K. M.; Guilard, R., Eds.; Academic Press: New York, 2000; Vol. 6.

(3) Stich, M. I. J.; Fischer, L. H.; Wolfbeis, O. S. Multiple fluorescent chemical sensing and imaging. Chem. Soc. Rev. 2010, 39, 3102-3114.

(4) (a) Zeis, R.; Siegrist, T.; Kloc, C. Single-crystal field-effect transistors based on copper phthalocyanine. Appl. Phys. Lett. 2005, 86, No. 022103. (b) Ma, P.; Chen, Y.; Cai, X.; Wang, H.; Zhang, Y.; Gao, Y.; Jiang, J. Organic field effect transistors based on 5,10,15,20tetrakis(4- pentyloxyphenyl)porphyrin single crystal. Synth. Met. 2010, $160,510-515$.

(5) (a) Walter, M. G.; Rudin, A. B.; Wamser, C. C. Porphyrins and phthalocyanines in solar photovoltaic cells. J. Porphyrins Phthalocyanines 2010, 14, 759-792. (b) Bottari, G.; de la Torre, G.; Guldiand, D. M.; Torres, T. Covalent and noncovalent phthalocyanine- carbon nanostructure systems: synthesis, photoinduced electron transfer, and application to molecular photovoltaics. Chem. Rev. 2010, 110, 67686816.

(6) Minari, T.; Seto, M.; Nemoto, T.; Isoda, S.; Tsukagoshi, K.; Aoyagi, Y. Molecular-packing-enhanced charge transport in organic field-effect transistors based on semiconducting porphyrin crystals. Appl. Phys. Lett. 2007, 91, No. 123501.

(7) Jiang, H.; Ye, J.; Hu, P.; Wei, F.; Du, K.; Wang, N.; Ba, T.; Feng, S.; Kloc, C. Fluorination of Metal Phthalocyanines: Single-Crystal Growth, Efficient N-Channel Organic Field-Effect Transistors, and Structure-Property Relationships. Sci. Rep. 2014, 4, No. 7573.

(8) Kim, J.; Soldatova, A. V.; Rodgers, M. A. J.; Kenney, M. E. The Synthesis and Characterization of a Group of Transition Metal Octabutoxynaphthalocyanines and the Absorption and Emission Properties of the $\mathrm{Co}, \mathrm{Rh}, \mathrm{Ir}, \mathrm{Ni}, \mathrm{Pd}$ and Pt Members of This Group. Polyhedron 2013, 57, 64-69.
(9) Bao, Z.; Lovinger, A. J.; Brown, J. New Air-Stable $n$-Channel Organic Thin Film Transistors. J. Am. Chem. Soc. 1998, 120, 207208.

(10) Tang, Q.; Li, H.; Liu, Y.; Hu, W. High-performance air-stable ntype transistors with an asymmetrical device configuration based on organic single-crystalline submicrometer/nanometer ribbons. J. Am. Chem. Soc. 2006, 128, 14634-14639.

(11) Łapok, Ł.; Obłoza, M.; Nowakowska, M. Highly Thermostable, Non-oxidizable Indium, Gallium, and Aluminium Perfluorophthalocyanines with n-Type Character. Chem. - Eur. J. 2016, 22, 1205012060.

(12) Bhupathiraju, N. V. S. D. K.; Rizvi, W.; Batteas, J. D.; Drain, C. M. Fluorinated porphyrinoids as efficient platforms for new photonic materials, sensors, and therapeutics. Org. Biomol. Chem. 2016, 14, 389-408.

(13) Yi, W.-B.; Ma, J. J.; Janng, L.-Q.; Cai, C.; Zhang, W. Synthesis and uses of fluorous and highly fluorinated macrocyclic and spherical molecules. J. Fluorine Chem. 2014, 157, 84-105.

(14) Karmann, E.; Meyer, J.-P.; Schlettwein, D.; Jaeger, N. I.; Anderson, M.; Schmidt, A.; Armstrong, N. R. Photoelectrochemical effects and (photo) conductivity of "n-type" phthalocyanines. Mol. Cryst. Liq. Cryst. Sci. Technol., Sect. A 1996, 283, 283-291.

(15) Hatay, I.; Su, B.; Mendez, M. A.; Corminboeuf, C.; Khoury, T.; Gros, C. P.; Bourdillon, M.; Meyer, M.; Barbe, J.-M.; Ersoz, M.; Zális, S.; Samec, Z.; Giraul, H. H. Oxygen reduction catalyzed by a fluorinated tetraphenylporphyrin free base at liquid/liquid interfaces. J. Am. Chem. Soc. 2010, 132, 13733-13741.

(16) Ellis, P. E., Jr.; Lyons, J. E. Effect of fluorination of the mesophenyl groups on selective tetraphenylporphyrinatoiron(III)-catalysed reactions of propane with molecular oxygen. J. Chem. Soc., Chem. Commun. 1989, 1315-1316.

(17) Ellis, P. E., Jr.; Lyons, J. E. Effect of fluorination of the mesophenyl groups on selective tetraphenylporphyrinatometal(III)-catalysed reactions of isobutane with molecular oxygen. J. Chem. Soc., Chem. Commun. 1989, 1189-1190.

(18) Goslinski, T.; Piskorz, J. Fluorinated porphyrinoids and their biomedical applications. J. Photochem. Photobiol., C 2011, 12, 304321.

(19) Schwerdtfeger, P. Table of Experimental and Calculated Static Dipole Polarizabilities for the Electronic Ground States of the Neutral Elements (in Atomic Units). http://ctcp.massey.ac.nz/dipolepolarizabilities, 2017

(20) Babudri, F.; Farinola, G. M.; Naso, F.; Ragni, R. Fluorinated organic materials for electronic and optoelectronic applications: the role of the fluorine atom. Chem. Commun. 2007, 1003-1022.

(21) Brinkmann, H.; Kelting, C.; Makarov, S.; Tsaryova, O.; Schnurpfeil, G.; Wöhrle, D.; Schlettwein, D. Fluorinated phthalocyanines as molecular semiconductor thin films. Phys. Status Solidi A 2008, 205, 409-420.

(22) de Oteyza, D. G.; El-Sayed, A.; Garcia-Lastra, J. M.; Goiri, E.; Krauss, T. N.; Turak, A.; Barrena, E.; Dosch, H.; Zegenhagen, J.; Rubio, A.; Wakayama, Y.; Ortega, J. E. Copper-phthalocyanine based metal-organic interfaces: The effect of fluorination, the substrate, and its symmetry. J. Chem. Phys. 2010, 133, No. 214703.

(23) Berger, R.; Resnati, G.; Metrangolo, P.; Weber, E.; Hulliger, J. Organic fluorine compounds: a great opportunity for enhanced materials properties. Chem. Soc. Rev. 2011, 40, 3496-3508.

(24) Reichenbächer, K.; Süss, H. I.; Hulliger, J. Fluorine in crystal engineering-"the little atom that could". Chem. Soc. Rev. 2005, 34, $22-30$.

(25) Mountford, P. Dibenzotetraaza [14] annulenes: versatile ligands for transition and main group metal chemistry. Chem. Soc. Rev. 1998, 27, 105-116.

(26) Bansal, V. K.; Kumar, R.; Prasad, R.; Prasad, S.; Niraj, U. Catalytic chemical and electrochemical wet oxidation of phenol using new copper(II) tetraazamacrocycle complexes under homogeneous conditions. J. Mol. Catal. A: Chem. 2008, 284, 69-76.

(27) Caiut, J. M. A.; Nakagaki, S.; Friedermann, G. R.; Drechsel, S. M.; Zarbin, A. J. G. Nickel (II) and manganese (III) tetraazaannu- 
lenes complexes encapsulated in porous Vycor glass (PVG): investigation of catalytic activity. J. Mol. Catal. A: Chem. 2004, 222, 213-222.

(28) Paschke, J.; Kirsch, M.; Korth, H. G.; de Groot, H.; Sustmann, R. Catalase-Like Activity of a Non-Heme Dibenzotetraaza [14] annulene-Fe (III) Complex under Physiological Conditions. J. Am. Chem. Soc. 2001, 123, 11099.

(29) Sustmann, R.; Korth, H.-G.; Kobus, D.; Baute, J.; Seiffert, K.H.; Verheggen, E.; Bill, E.; Kirsch, M.; de Groot, H. Fe ${ }^{\text {III }}$ Complexes of 1,4,8,11-Tetraaza[14]annulenes as Catalase Mimics. Inorg. Chem. 2007, 46, 11416-11430.

(30) Wang, X.; Li, S.; Jiang, Y. Mechanism of $\mathrm{H}_{2} \mathrm{O}_{2}$ Dismutation Catalyzed by a New Catalase Mimic (a Non-Heme Dibenzotetraaza[14]annulene-Fe(III) Complex): A Density Functional Theory Investigation. Inorg. Chem. 2004, 43, 6479-6489.

(31) Bin, Y.; Zhao, F.; Huang, L.; Li, Z.; Zhang, F. Dibenzotetraaza [14] annulene materials for recordable blue laser optical disc. Proc. SPIE 2007, 6827, No. 682712.

(32) Lin, L.-S.; Marks, T. J.; Kannewurf, C. R.; Lyding, S. W.; McClure, M.; Ratajack, M. T.; Whang, T.-C. New class of electrically conductive metallomacrocycles: iodine-doped dihydrodibenzo[ $b, i]$ $[1,4,8,11]$ tetra-azacyclotetradecine complexes. J. Chem. Soc., Chem. Commun. 1980, 954-955.

(33) Khaledi, H.; Olmstead, M. M.; Ali, H. M.; Thomas, N. F. Indolenine meso-Substituted Dibenzotetraaza[14]annulene and Its Coordination Chemistry toward the Transition Metal Ions $\mathrm{Mn}^{\mathrm{III}}$, $\mathrm{Fe}^{\mathrm{III}}, \mathrm{Co}^{\mathrm{II}}, \mathrm{Ni}^{\mathrm{II}}, \mathrm{Cu}^{\mathrm{II}}$, and $\mathrm{Pd}^{\mathrm{II}}$. Inorg. Chem. 2013, 52, 1926-1941.

(34) Lukes, P. J.; Crayston, J. A.; Ando, D. J.; Harman, M. E.; Hursthouse, M. B. Crystal structures of $\mathrm{H}_{2}\left[\mathrm{Me}_{2}\right.$ dibenzo[14]tetraene]$\mathrm{N}_{4}$ and $\mathrm{H}_{2}\left[\mathrm{Me}_{2}\right.$ dixylyl[14] tetraene $] \mathrm{N}_{4}$ : new tetraaza macrocycles. $J$. Chem. Soc., Perkin Trans. 2 1991, 1845-1849.

(35) Weiss, M. C.; Gordon, G.; Goedken, V. L. Crystal and molecular structure of the macrocyclic nickel(II) complex [Ni $\left.\left(\mathrm{C}_{18} \mathrm{H}_{14} \mathrm{~N}_{4}\right)\right]$ : dibenzo[b, i] $[1,4,8,11]$ tetraaza[14] annulenenickel(II). Inorg. Chem. 1977, 16, 305-310.

(36) Weiss, M. C.; Goedken, V. L. Chemistry of the macrocyclic cobalt(II) complex, $\left[\mathrm{Co}\left(\mathrm{C}_{22} \mathrm{H}_{22} \mathrm{~N}_{4}\right)\right]$. Reactions with halogens, molecular oxygen, alkynes, and nitriles. J. Am. Chem. Soc. 1976, 98, 3389-3392.

(37) Whyte, A. M.; Yoshiaki, S.; Nichol, G. S.; Matsushita, M. M.; Awaga, K.; Robertson, N. Planar $\mathrm{Ni}(\mathrm{II}), \mathrm{Cu}(\mathrm{II})$ and $\mathrm{Co}(\mathrm{II})$ tetraaza[14]annulenes: structural, electronic and magnetic properties and application to field effect transistors. J. Mater. Chem. 2012, 22, 17967-17975.

(38) Hiller, H.; Dimroth, P.; Pfitzner, H. 5.14-Dihydro-dibenzo[b.i][5.9.14.18] tetraaza[14]annulen, ein makrocyclischer ChelatBildner. Justus Liebigs Ann. Chem. 1968, 717, 137-147.

(39) Purrington, S. T.; Knight, B. W.; Bereman, R. D. Fluorinesubstituted tetraazaannulene complexes: syntheses and characterizations. Inorg. Chim. Acta 1994, 223, 187-191.

(40) Azuma, N.; Tani, H.; Ozawa, T.; Niida, H.; Tajima, K.; Sakatad, K. A crystal modification of dibenzo[b,i] $[1,4,8,11]$ tetraaza[14]annulene: X-ray molecular structure and proton tautomerism of the highly $\pi$-conjugated form. J. Chem. Soc., Perkin Trans. 2 1995, 343348.

(41) Spackman, M. A.; Byrom, P. G. A novel definition of a molecule in a crystal. Chem. Phys. Lett. 1997, 267, 215-220.

(42) Spackman, M. A.; Jayatilaka, D. Hirshfeld surface analysis. CrystEngComm 2009, 11, 19-32.

(43) McKinnon, J. J.; Spackman, M. A.; Mitchell, A. S. Novel tools for visualizing and exploring intermolecular interactions in molecular crystals. Acta Crystallogr., Sect. B: Struct. Sci., Cryst. Eng. Mater. 2004, 60, 627-668.

(44) Spackman, M. A.; McKinnon, J. J. Fingerprinting intermolecular interactions in molecular crystals. CrystEngComm 2002, 4, 378-392.

(45) McKinnon, J. J.; Jayatilaka, D.; Spackman, M. A. Towards quantitative analysis of intermolecular interactions with Hirshfeld surfaces. Chem. Commun. 2007, 3814-3816.
(46) Browning, C.; Hudson, J. M.; Reinheimer, E. W.; Kuo, F.-L.; McDougald, R. N., Jr.; Rabaâ, H.; Pan, H.; Bacsa, J.; Wang, X.; Dunbar, K. R.; Shepherd, N. D.; Omary, M. A. Synthesis, Spectroscopic Properties, and Photoconductivity of Black Absorbers Consisting of $\mathrm{Pt}$ (Bipyridine)(Dithiolate) Charge Transfer Complexes in the Presence and Absence of Nitrofluorenone Acceptors. J. Am. Chem. Soc. 2014, 136, 16185-16200.

(47) Thompson, M. A. ArgusLab 4.0.1; Planaria Software LLC: Seattle, WA, USA, 2004. http://www.arguslab.com/arguslab.com/ ArgusLab.html.

(48) Politzer, P.; Timberlake, J. W. Anomalous Properties of Halogen Substituents. J. Org. Chem. 1972, 37, 3557-3559.

(49) Clark, T.; Hennemann, M.; Murray, J. S.; Politzer, P. Halogen bonding: the $\sigma$-hole. J. Mol. Model. 2007, 13, 291-296.

(50) Heaton, A.; Hill, M.; Drakesmith, F. Polyhalogenonitrobenzenes and derived compounds Part 5. Improved preparations of 1,2,3,4-tetrafluoro-5,6-dinitrobenzene and 3,4,5,6-tetrafluoro-1,2-phenylenediamine, and the use of the latter for the synthesis of tetrafluorobenzheterocycles. J. Fluorine Chem. 1997, 81, 133-138.

(51) Sauer, J. C.; Sheehan, J. C.; Gilmont, E. R. Propiolaldehyde. Org. Synth., Coll. 1963, 4, 813-815.

(52) CrystalClear: Rigaku Corporation. CrystalClear Software User's Guide, Molecular Structure Corporation; Rigaku Corporation, 1999.

(53) Altomare, A.; Burla, M.; Camalli, M.; Cascarano, G.; Giacovazzo, C.; Guagliardi, A.; Moliterni, A.; Polidori, G.; Spagna, R. SIR97: a new tool for crystal structure determination and refinement. J. Appl. Crystallogr. 1999, 32, 115-119.

(54) Beurskens, P. T.; Admiraal, G.; Beurskens, G.; Bosman, W. P.; de Gelder, R.; Israel, R.; Smits, J. M. M. The DIRDIF-99 Program System, Technical Report of the Crystallography Laboratory; University of Nijmegen: The Netherlands, 1999.

(55) CrystalStructure 3.8: Crystal Structure Analysis Package; Rigaku and Rigaku Americas: TX, 2000-2007.

(56) Sheldrick, G. M. SHELXL-97: Program for Crystal Structure Refinement; University of Göttingen: Göttingen, Germany, 1997.

(57) Pilia, L.; Pizzotti, M.; Tessore, F.; Robertson, N. Nonlinearoptical properties of $\alpha$-diiminedithiolatonickel (II) complexes enhanced by electron-withdrawing carboxyl groups. Inorg. Chem. 2014, 53, 4517-4526.

(58) Parr, R. G.; Yang, W. Density Functional Theory of Atoms and Molecules; Oxford University Press: Oxford, 1989.

(59) Frisch, M. J.; Trucks, G. W.; Schlegel, H. B.; Scuseria, G. E.; Robb, M. A.; Cheeseman, J. R.; Scalmani, G.; Barone, V.; Mennucci, B.; Petersson, G. A.; Nakatsuji, H.; Caricato, M.; Li, X.; Hratchian, H. P.; Izmaylov, A. F.; Bloino, J.; Zheng, G.; Sonnenberg, J. L.; Hada, M.; Ehara, M.; Toyota, K.; Fukuda, R.; Hasegawa, J.; Ishida, M.; Nakajima, T.; Honda, Y.; Kitao, O.; Nakai, H.; Vreven, T.; Montgomery, J. A., Jr.; Peralta, J. E.; Ogliaro, F.; Bearpark, M.; Heyd, J. J.; Brothers, E.; Kudin, K. N.; Staroverov, V. N.; Kobayashi, R.; Normand, J.; Raghavachari, K.; Rendell, A.; Burant, J. C.; Iyengar, S. S.; Tomasi, J.; Cossi, M.; Rega, N.; Millam, N. J.; Klene, M.; Knox, J. E.; Cross, J. B.; Bakken, V.; Adamo, C.; Jaramillo, J.; Gomperts, R.; Stratmann, R. E.; Yazyev, O.; Austin, A. J.; Cammi, R.; Pomelli, C.; Ochterski, J. W.; Martin, R. L.; Morokuma, K.; Zakrzewski, V. G.; Voth, G. A.; Salvador, P.; Dannenberg, J. J.; Dapprich, S.; Daniels, A. D.; Farkas, Ö; Foresman, J. B.; Ortiz, J. V.; Cioslowski, J.; Fox, D. J. Gaussian 09, revision D.01; Gaussian, Inc.: Wallingford, CT, 2009.

(60) Becke, A. D. Density-functional thermochemistry. III. The role of exact exchange. J. Chem. Phys. 1993, 98, 5648-5652.

(61) Lee, C.; Yang, W.; Parr, R. G. Development of the ColleSalvetti correlation-energy formula into a functional of the electron density. Phys. Rev. B 1988, 37, 785-789.

(62) (a) Krishnan, R.; Binkley, J. S.; Seeger, R.; Pople, J. A. Selfconsistent molecular orbital methods. XX. A basis set for correlated wave functions. J. Chem. Phys. 1980, 72, 650-654. (b) McLean, A. D.; Chandler, G. S. Contracted Gaussian basis sets for molecular calculations. I. Second row atoms, $\mathrm{Z}=11-18$. J. Chem. Phys. 1980, $72,5639-5648$. 
(63) Espa, D.; Pilia, L.; Marchiò, L.; Mercuri, M. L.; Serpe, A.; Sessini, E.; Deplano, P. Near-infrared pigments based on ion-pair charge transfer salts of dicationic and dianionic metal-dithiolene [M (II) $=$ Pd, Pt] complexes. Dalton Trans. 2013, 42, 12429-12439.

(64) Wolff, S. K.; Grimwood, D. J.; McKinnon, J. J.; Turner, M. J.;

Jayatilaka, D.; Spackman, M. A. CrystalExplorer (Version 3.1);

University of Western Australia, 2012. 